\title{
Dieta hiperlipídico-proteica utilizada para emagrecimento induz obesidade em ratos
}

\author{
Low-carbohydrate diet used for weight loss \\ induces obesity in rats
}

Alberto José de BORBA²

Márcia Gabriela Margato ROCHA ${ }^{3}$

Marcelo Fernandes da SILVA²

Denise Teresinha de Sales TIBÚRCIO²

Sanívia Aparecida de Lima PEREIRA²

Luiz Carlos dos REIS 3

Geraldo THEDEI JÚNIOR²

RE S U M O

\section{Objetivo}

Neste trabalho, analisa-se o efeito de dieta hiperlipídico-proteica com baixo teor de carboidrato sobre o peso corporal, peso de órgãos, consumo de ração, parâmetros bioquímicos e alterações histopatológicas no fígado de ratos.

\section{Métodos}

Foram utilizados 24 animais - 12 no grupo-controle e 12 no grupo-experimental - com peso médio de 160 gramas no início do experimento. Semanalmente, foram verificados o peso corporal e o consumo de ração, e ao final de oito semanas foram feitas as dosagens bioquímicas sanguíneas, pesagem de órgãos e análise histopatológica dos fígados.

\section{Resultados}

Os animais do grupo-experimental tiveram maior ganho de peso corporal e acumularam mais tecido adiposo que os animais do grupo-controle. Fígado, rins e baço não sofreram alterações quanto ao peso. Os animais que receberam dieta hiperlipídico-proteica tiveram um aumento na ingestão energética acumulada nas oito semanas do estudo. O grupo-experimental desenvolveu hiperglicemia e hipertrigliceridemia, aumento da fração lipoproteína de alta densidade do colesterol e da creatinina sérica quando comparado ao grupo-controle. Foi detectada esteatose hepática no grupo-experimental.

\footnotetext{
1 Artigo elaborado a partir da dissertação de A.J. BORBA, intitulada "Efeito da dieta hiperlipídico-proteica no metabolismo de ratos Wistar adultos". Universidade Federal do Triângulo Mineiro; 2008.

2 Universidade de Uberaba, Laboratório de Nutrição e Alimentação. Av. Nenê Sabino, 1801, 38055-500, Uberaba, MG, Brasil. Correspondência para/Correspondence to: G. THEDEI JÚNIOR. E-mail: <geraldo.thedei@uniube.br>.

3 Universidade Federal do Triângulo Mineiro, Departamento de Ciências Biológicas. Uberaba, MG, Brasil.
} 
520 | A.J. BORBA et al.

\section{Conclusão}

Os resultados demonstraram que dietas pobres em carboidratos e ricas em gordura e proteínas podem acarretar alterações metabólicas prejudiciais ao organismo.

Termos de indexação: Carboidratos. Dieta. Lipídeos. Metabolismo. Proteínas. Rato.

\section{A B S T R A C T}

\section{Objective}

This study analyzed the effect of a high fat, high protein and low carbohydrate diet on the body weight, organ weight, food intake and biochemical parameters of rats and the histopathological changes in their livers.

\section{Methods}

A total of 24 animals were used, 12 in the control group and 12 in the experimental group, with a mean weight of 160 grams at baseline. Body weight and food intake were collected weekly. At the end of 8 weeks, the animals were killed for the biochemical tests and weighing of organs and the livers were submitted to histopathological analysis.

\section{Results}

The animals in the experimental group gained more weight and accumulated more body fat than the animals in the control group. The weight of the liver, kidneys and spleen did not change. The animals fed the low carbohydrate diet consumed more calories during the 8 weeks of the study period. They also developed hyperglycemia and hypertriglyceridemia and presented high high-density lipoprotein cholesterol and serum creatinine. The experimental group also presented hepatic steatosis.

\section{Conclusion}

The results show that low carbohydrate diets that are rich in fats and proteins may result in harmful metabolic changes in rats.

Indexing terms: Carbohydrates. Diet. Lipids. Metabolism. Proteins. Rat.

\section{N T R O D U Ç Ã O}

A obesidade pode ser considerada um grave problema de saúde pública em muitos países do mundo e está associada a fator predisponente e coexistente com doenças cardiovasculares, metabólicas e neurais, como hipertensão arterial, trombose, acidente vascular cerebral e diabetes ${ }^{1}$. A obesidade é consequência de vários fatores genéticos e ambientais, incluindo hábitos alimentares incorretos e falta de atividade física. A obesidade, juntamente com vários fatores de risco metabólicos, tais como resistência à insulina, níveis plasmáticos elevados de Triglicérides (TG) e baixos níveis de Lipoproteína de Alta Densidade $(\mathrm{HDL})$, está relacionada a uma redução da expectativa de vida em países desenvolvidos e em desenvolvimento ${ }^{2,3}$.

O papel do tecido adiposo como um regulador da homeostase de lipídeos e da glicose surgiu de muitas evidências experimentais, como a demonstração de que elevados níveis de Ácidos Graxos Livres ( $A G L$ ) no sangue se correlacionam com a resistência periférica à insulina ${ }^{4}$.

O desequilíbrio dietético em macronutrientes está associado a alterações metabólicas. Em estudo anterior, foi demonstrado que ratos alimentados com dieta rica em gordura durante cinco semanas tiveram sobrepeso, hiperlipidemia e hiperleptinemia, e um retardo do clearance de glicose, provavelmente causado por um aumento de AGL na circulação ${ }^{5}$. Em concordância, outro estudo demonstrou que, após dieta rica em gordura durante 12 semanas, os ratos tinham aumentado significativamente o peso corporal, a pressão arterial sistólica, a insulinemia, a glicemia e a trigliceridemia, bem como a albumina urinária, quando comparados com aqueles alimentados com uma dieta com baixo teor de gordura ${ }^{6}$. Além disso, a 
dieta rica em gordura também induziu infiltração hepática e redução dos receptores de glucagon na membrana celular, com repercussão no metabolismo geral e especialmente no da glicose $^{7}$. Porém, dietas com alta relação proteína/ carboidrato (53\% de proteína do leite) causam um menor ganho de peso associado com uma menor deposição de gordura e redução na proporção dos adipócitos grandes, provavelmente devido à redução da ingestão alimentar. Além disso, foi observada uma melhora na tolerância à glicose e na sensibilidade à insulina quando comparados com animais submetidos a uma dieta com alta de sacarose ${ }^{8}$. Em outro estudo, foi demonstrado que um aumento do teor de proteína - 15-30\% induziu uma menor ingestão energética, provavelmente devido ao aumento da sensibilidade à leptina, resultando em uma redução significativa do peso. Esse efeito anoréxico do teor de proteínas pode contribuir para perda de peso induzida pela dieta de baixo teor de carboidratos 9 .

Embora existam muitos estudos sobre dietas hiperlipídicas ou hiperproteicas, os que determinam o efeito da presença simultânea de excesso de proteína e de lipídeos são menos presentes, embora dietas desse tipo sejam frequentemente utilizadas pela população. Curiosamente, ratos alimentados com uma dieta hiperproteica e hiperlipídica ( $55 \%$ e $45 \%$ do total de energias fornecidas por proteínas e lipídeos, respectivamente) e sem carboidratos apresentam menor consumo de alimentos e, consequentemente, menor ganho de peso corporal que os que foram alimentados com dieta apenas com baixo teor de carboidratos ou normoglicídica. O menor peso corporal causado por dietas pobres em carboidratos é, pelo menos em parte, devido a uma menor deposição de gordura e um menor consumo de energia, que são observados em animais submetidos à restrição de carboidratos ${ }^{10}$.

Assim sendo, o objetivo deste trabalho foi avaliar o efeito de uma dieta com alto teor de proteína (50\% em peso, 31\% em energias) e lipídeos ( $45 \%$ em peso, $66 \%$ em energias) e baixo teor de carboidratos (5\% em peso, 3\% em energias) - uma composição similar às dietas sugeridas para perda de peso corporal - no ganho de peso, nos parâmetros bioquímicos, no peso de órgãos e na histologia hepática de ratos Wistar adultos.

\section{MÉ TODOS}

O estudo foi aprovado pelo Comitê de Ética em Experimentação Animal (CEEA) da Universidade de Uberaba, sob número CEEA 007/2008. Ratos Wistar (Média-M=160g, Desvio-Padrão$-D P=8 g$ ) foram alojados individualmente em gaiolas metabólicas de arame de aço inoxidável em ambiente com temperatura de $m=24^{\circ} \mathrm{C}$, $\mathrm{DP}=2^{\circ} \mathrm{C}$, com ciclo claro/escuro: 12 horas de luz e 12 horas de escuro.

Os animais foram separados em grupo-controle ( $n=12)$, que recebeu alimentação balanceada (ração comercial para ratos), e grupo-experimental $(n=12)$, alimentado com dieta rica em proteína (31\% do total de energias, como caseína de leite) e lipídeo ( $66 \%$ do total de energias, como banha de porco) e pobre em carboidrato ( $3 \%$ das energias totais, como sacarose). A ingestão de alimentos e o peso corporal foram monitorados semanalmente, durante oito semanas. Nesse período, a alimentação e a água foram fornecidas ad libitum.

No final do período de estudo, os animais foram submetidos à privação de ração durante a noite e eutanasiados pela manhã com injeção intraperitoneal de pentobarbital sódico $(50 \mathrm{mg} / \mathrm{kg}$ de peso corporal), seguida de laparotomia e incisão do diafragma.

O sangue foi coletado por punção da veia cava inferior e centrifugado a $12000 \times$ g por 15 minutos para separação do soro. Órgãos e tecidos foram retirados e pesados após a eliminação de fáscias e gordura adjacente. $O$ peso dos órgãos e tecidos foi expresso em unidades normalizadas correspondentes ao grama de órgão/100g de peso corporal.

\section{Composição das dietas}

A dieta do grupo-controle continha carbonato de cálcio, farinha de milho integral, farelo 
de arroz, farelo de soja, farelo de trigo, fosfato bicálcico, melado de cana, cloreto de sódio, óleo de soja, complexo de vitaminas e minerais e foi adquirida de $L A B C I{ }^{\circledR}$, São Paulo, Brasil. A composição centesimal da dieta-controle era assim constituída: carboidrato $56 \%$, proteína $23 \%$, gordura $3 \%$, fibra $8 \%$, umidade $10 \%$.

A dieta experimental continha: caseína de leite $45,4 \%$, banha de porco $44,3 \%$, sacarose $5,0 \%$, celulose microcristalina $0,2 \%$, Pré-mix vitamínico Rhoster ${ }^{\circledR}$ AIN 93 1,0\%, Pré-mix mineral AIN 93M Rhoster ${ }^{\circledast} 3,5 \%$, L-cistina 0,3\%, bitartarato de colina $0,1 \%$ e colesterol $0,1 \%$. Todos os ingredientes foram misturados em batedeira industrial e armazenados em alíquotas de 500g, à temperatura de $-20^{\circ} \mathrm{C}$ até o uso.

\section{Parâmetros bioquímicos}

Todos os parâmetros bioquímicos do sangue foram determinados com o analisador semiautomatizado Bioplus- $2000^{\circledR}$, que utiliza amostras de soro não hemolisado e quites comerciais enzimáticos ou colorimétricos (Gold Analysa ${ }^{\circledR}$, São Paulo, Brasil). Em todas as dosagens foi feita uma curva de calibração com amostras fornecidas pelo fabricante. A Lipoproteína de Baixa Densidade (LDL-colesterol) foi determinado pela fórmula: $L D L=(T C O-H D L)-(T G / 5)$, onde $T C O=$ Colesterol Total, $\mathrm{HDL}=$ Lipoproteína de Densidade Alta e $\mathrm{TG}=$ Triglicérides .

\section{Análise histológica do fígado}

Os fígados foram mantidos em formalina tamponada (formol 10\%, pH 7,0) por um tempo mínimo de 10 dias, após o qual foi feito o processamento histológico de rotina: desidratação em série crescente de álcool etílico, diafanização em xilol e inclusão em parafina; corte com $6 \mu \mathrm{m}$ de espessura e coloração com hematoxilina eosina. As observações dos cortes histológicos foram realizadas por microscopia de luz comum por meio de um microscópio da marca Zeiss modelo
Axioskop ${ }^{\circledR}$, e as imagens foram capturadas por uma câmera digital Sanyo ${ }^{\circledR}$. A avaliação da esteatose foi realizada de forma semiquantitativa e classificada em ausente, discreta, moderada e acentuada. Considerou-se ausente quando não havia esteatose em nenhuma porção analisada do corte; discreta quando comprometia entre $25 \%$ e $50 \%$ do corte; moderada quando acometia entre $51 \%$ e $75 \%$ do corte, e acentuada com acometimento acima de $75 \%$ do corte ${ }^{11}$.

Os resultados individuais de todos os parâmetros de cada rato dos grupos-experimental e controle foram inseridos em planilha eletrônica para análise estatística. A análise dos valores foi feita pelo software estatístico GraphPad Prism 4 for Windows ${ }^{\circledR}$, tendo sido efetuada análise comparativa através de teste T não-pareado, considerando-se o valor de $p<0,05$ como nível de significância para diferença entre os grupos. Nas Tabelas e Figuras os resultados foram expressos como média e desvio-padrão da média.

\section{RESULTA DOS}

\section{Peso corporal}

A partir da segunda semana de experimento, o peso médio dos ratos do grupo experimental foi superior ao dos ratos do grupo-controle, mas só após a $5^{\mathrm{a}}$ semana essa diferença foi estatisticamente significativa $(p<0,05)$ (Figura 1).

\section{Ingestão alimentar}

A ingestão de ração, medida em gramas ingeridas/animal, foi significativamente menor no grupo-experimental do que no grupo-controle em todas as oito semanas do experimento $(p<0,001$, dados não mostrados). Em termos energéticos, a ingestão pelos animais do grupo-experimental foi semelhante aos animais do grupo-controle, exceto nas semanas 1, 4 e 5, quando houve maior consumo energético pelo grupo-experimental (Figura 2). Quando se analisa a ingestão acumulada de 
energia ao longo das oito semanas pelos animais de cada grupo, observa-se uma ingestão energética significativamente maior $(p<0,05)$ nos ratos do grupo-experimental $(3.963,1 \mathrm{kcal} / \mathrm{animal}) \mathrm{em}$ relação aos animais do grupo-controle (3.479,8 $\mathrm{kcal} / \mathrm{animal})$.

\section{Peso de órgãos e tecidos}

Os animais do grupo-experimental não apresentaram diferenças quanto ao peso do fíga-

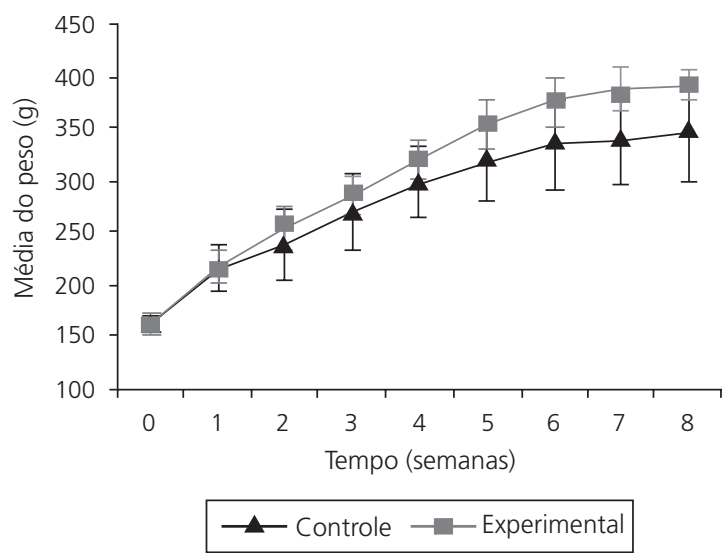

Figura 1. Peso médio (gramas) dos animais do grupo-controle e experimental ao final de cada semana do estudo. Uberaba (MG), 2008.

Nota: Dados $=$ média e desvio-padrão $\left({ }^{*} p<0,05\right)$.

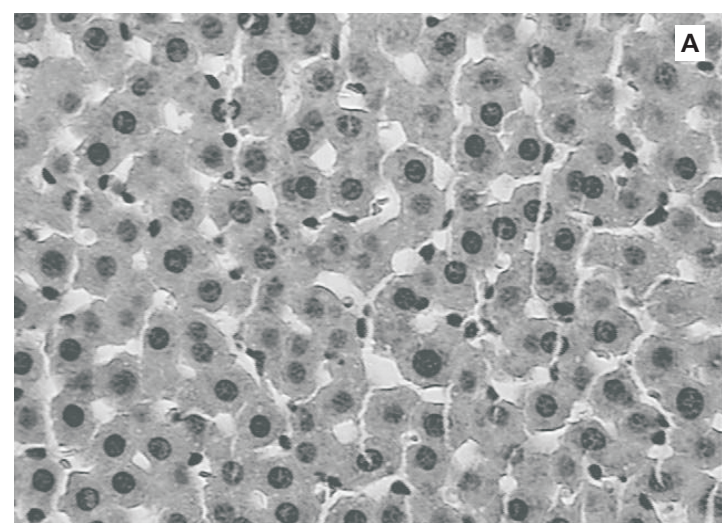

do, rins, músculo tibial anterior e baço em relação aos animais do grupo-controle. Os animais do grupo-experimental tiveram aumento tanto da gordura perirrenal quanto periepididimal quando comparados ao grupo-controle $(p<0,01)$ (Tabela1).

\section{Análise histológica do fígado}

Foi observada frequência de 5,5\% de esteatose (de grau discreto) no grupo-controle, contra $16,7 \%$ de esteatose discreta, $44,5 \%$ mode-

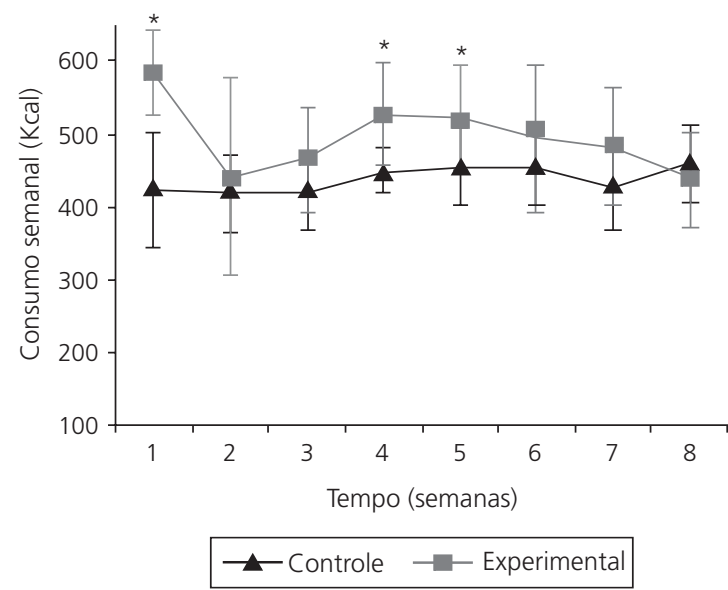

Figura 2. Consumo médio semanal de ração (kcal) pelos animais do grupo-controle e experimental. Uberaba (MG), 2008.

Nota: Dados $=$ média e desvio-padrão $\left({ }^{*} p<0,05\right)$.

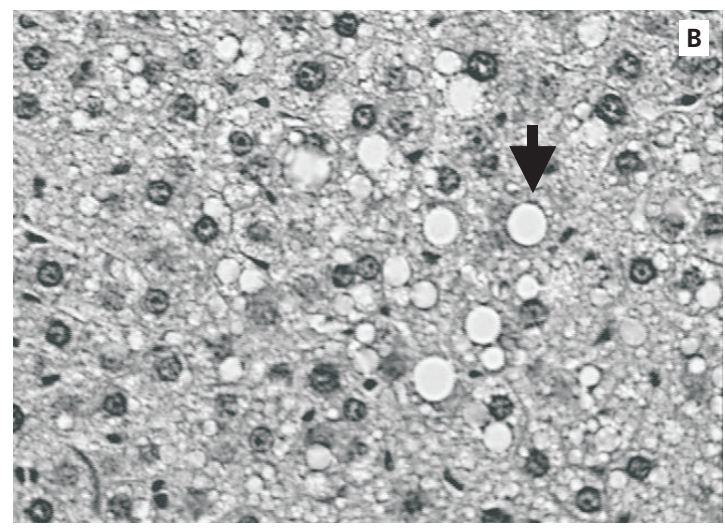

Figura 3. Corte histológico de fígado de animal do grupo-controle (A) e experimental (B) (Hematoxilina e Eosina, 800x). Uberaba (MG), 2008.

Nota: A seta indica esteatose. 
rada e $38,8 \%$ de esteatose acentuada no grupo-experimental $(p<0,001)$ (Figura 3). Foi observado também infiltrado inflamatório em pequena intensidade, sem diferença entre os grupos de animais (dados não mostrados).

\section{Parâmetros bioquímicos}

Os animais do grupo-experimental apresentaram aumento significativo da glicose quando comparados aos animais do grupo-controle $(p<0,05)$. A dieta hiperlipídico-proteica (HLP) causou um aumento significativo nos níveis de triglicerídeos dos animais do grupo-experimental, quando comparados ao grupo $C(p<0,05)$. A fração LDL do colesterol assim como o colesterol total não apresentaram diferença estatisticamente

Tabela 1. Peso relativo ( $g / 100 \mathrm{~g}$ de peso corporal) dos órgãos e tecidos dos animais do grupo-controle e do experimental. Uberaba (MG), 2008.

\begin{tabular}{lcccccc}
\hline & \multicolumn{2}{c}{ Controle } & & \multicolumn{2}{c}{ Experimental } \\
\cline { 2 - 3 } \cline { 5 - 6 } & M & DP & & M & DP \\
\hline Fígado & 3,36 & 0,42 & & 3,53 & 0,37 \\
Rins & 0,86 & 0,10 & & 0,88 & 0,062 \\
Músculo & 0,23 & 0,036 & & 0,24 & 0,043 \\
G. P. Renal & 0,86 & 0,48 & & 1,89 & $0,74^{*}$ \\
G. P. Epidid. & 1,11 & 0,27 & & 2,10 & $0,51^{*}$ \\
Baço & 0,27 & 0,039 & & 0,29 & 0,061 \\
\hline
\end{tabular}

M: médias; DP: desvio-padrão; ( $\left.{ }^{*} p<0,01\right)$.

Tabela 2. Dosagens bioquímicas de glicose (GLI), Triglicerídeos (TRI), Colesterol total (COL), colesterol HDL, colesterol LDL, Ureia (URE), creatinina (CRE) e Cálcio (CAL), dos animais dos grupos-controle e experimental. Uberaba (MG), 2008

\begin{tabular}{lrrrrr}
\hline & \multicolumn{2}{c}{ Controle } & & \multicolumn{2}{c}{ Experimental } \\
\cline { 2 - 3 } \cline { 5 - 6 } & \multicolumn{1}{c}{$\mathrm{M}$} & \multicolumn{1}{c}{$\mathrm{DP}$} & & \multicolumn{1}{c}{$\mathrm{M}$} & $\mathrm{DP}$ \\
\hline GLI & 129,80 & 21,90 & & 172,40 & $58,0^{*} 0$ \\
TRI & 34,50 & 4,40 & & 47,00 & $13,70^{*}$ \\
COL & 37,60 & 13,10 & & 46,00 & 7,90 \\
HDL & 3,20 & 1,60 & & 7,80 & $3,30^{*}$ \\
LDL & 27,60 & 13,10 & & 28,70 & 7,60 \\
URE & 56,80 & 15,00 & & 51,80 & 11,00 \\
CRE & 0,49 & 0,09 & & 0,60 & 0,09 \\
CAL & 11,50 & 1,94 & & 10,80 & 1,00 \\
\hline
\end{tabular}

M: médias; DP: desvio-padrão; $\left({ }^{*} p<0,01\right)$. significativa entre os grupos. Entretanto, é possível observar que os níveis da fração HDL do colesterol apresentaram diferença estatisticamente significativa $(p<0,01)$ entre o grupo-controle e o experimental. Os resultados das dosagens da ureia e do cálcio séricos não apresentaram diferença significativa entre os grupos. Já os níveis de creatinina dos animais experimentais foram superiores quando comparados com os animais do grupo-controle $(p<0,05)$ (Tabela 2).

\section{I S C U S S Ã O}

Nesta pesquisa foi estudado o efeito de uma dieta hiperlipídico-proteica com baixo teor de carboidrato no metabolismo de ratos Wistar adultos.

Segundo Akiyama et al. ${ }^{12}$, ratos alimentados com dieta hiperenergética com alto teor de gorduras podem desenvolver obesidade. Neste estudo, embora o consumo energético semanal tenha sido semelhante para os dois grupos avaliados, observa-se que os animais do grupo-experimental tiveram maior ganho de peso quando comparados aos animais do grupo-controle, como reflexo de um consumo maior de energia ao longo das oito semanas de experimento. Com base nesses dados, pode-se afirmar que o maior ganho de peso dos animais do grupo-experimental foi causado pela maior ingestão energética proporcionada pela dieta HLP. Duarte et al. ${ }^{13}$ constataram que, mesmo sem alterar a quantidade diária de ração ingerida, a dieta hiperlipídica promoveu obesidade, fato que também se observa neste estudo.

Estadella et al. ${ }^{14}$ descreveram que uma dieta hiperlipídico-proteica aumentou a taxa de leptina na circulação sistêmica dos animais. Outro estudo de Fam et al. ${ }^{15}$ mostrou que uma dieta hiperlipídica causou diminuição na sensibilidade da leptina. Esses dados podem ajudar a explicar os resultados, pois uma reduzida sensibilidade à leptina, mesmo com níveis maiores desse hormônio, poderia justificar o ganho de peso dos animais, tendo em vista que uma das ações da leptina 
é a indução dos mediadores anorexígenos, tais como pró-opiomelanocortina (POMC) e transcrito regulado pela anfetamina e cocaína (CART), os quais inibem os mediadores orexígenos como neuropeptídeo Y (NPY) e peptídeo relacionado ao Agouti (AgRP), causando a indução do gasto energético com processos metabólicos "fúteis", como a geração de calor via termogenina ou proteína desacopladora e a diminuição do consumo de alimento ${ }^{16}$. Assim, com menor atividade de leptina, possivelmente devido a uma falha nessas vias reguladoras, o comportamento da alimentação não seria reduzido proporcionalmente ao aumento do tecido adiposo, como usualmente acontece em condições normais.

O maior peso corporal dos animais experimentais deveu-se, pelo menos em parte, ao maior depósito de gorduras nos adipócitos induzido pela dieta HLP, tendo em vista que a análise do peso da gordura perirrenal e periepididimal mostrou um significativo aumento desses tecidos nos animais experimentais (Tabela 1). Isso sugere que o aumento na massa corporal é reflexo do ganho de massa gorda, tendo em vista que os demais órgãos analisados (fígado, rins, músculo e baço) não apresentaram variação significativa entre os dois grupos. Resultados similares foram relatados por Woods et al. ${ }^{17}$, que mostraram que a quantidade de tecido adiposo foi maior em ratos que ingeriram dieta hiperlipídica. No entanto, esses autores relatam que o peso corporal foi similar entre os dois grupos, o que permite inferir que o excesso de proteína na dieta HLP compromete ainda mais o ganho de tecido adiposo, uma vez que se observa maior peso corporal nos animais experimentais e que proteínas e carboidratos são isoenergéticos. Em outras palavras, não só a densidade energética mas também a origem dessas energias (carboidratos ou proteínas) podem afetar o metabolismo e a deposição de gorduras, observação também relatada no estudo de Woods et al. ${ }^{17}$. Outro estudo realizado por Klaus ${ }^{18}$ mostra que o aumento da relação proteína-carboidrato de uma dieta com alto teor lipídico atrasa mas não previne o desenvolvimento da adiposidade.
Apesar de a dieta experimental ser pobre em carboidratos, os animais do grupo experimental apresentaram uma elevação significativa da glicemia e da trigliceridemia quando comparados ao grupo-controle. Esse aumento da glicemia provavelmente esteja associado ao aumento da quantidade de gordura corporal e também ao aumento de hormônios hiperglicemiantes: glucagon, adrenalina, cortisol e hormônio de crescimento ${ }^{19,20}$. Hábitos alimentares desbalanceados levaram às alterações bioquímicas séricas tais como hiperlipidemia, hiperinsulinemia e intolerância à glicose, como foi demonstrado por Akiyama et al. ${ }^{12}$ e Fernandes et al..21. Por esses motivos, é importante conhecer a associação entre o consumo de determinados alimentos e os níveis de lipídeos séricos ${ }^{22}$, uma vez que a dislipidemia pode desencadear o aparecimento de aterosclerose e outras doenças. Os dados do presente estudo, no entanto, contrapõem-se àqueles de Duarte et al. ${ }^{13}$, que demonstraram que a obesidade provocada pela dieta hiperlipídica palatável não alterou os níveis de glicose e insulina de jejum dos animais.

Os níveis de colesterol total se mostraram aumentados no grupo-experimental, porém não houve diferença estatisticamente significativa quando comparados ao controle, sugerindo que o nível desse metabólito não responde sempre com acréscimo em resposta ao aumento no teor lipídico do alimento. A fração LDL também não apresentou alterações significativas. No entanto, a fração HDL dos animais experimentais elevou-se consideravelmente em relação ao controle. Esse aumento da fração HDL pode ser explicado pela grande quantidade de gorduras monoinsaturadas presentes nas dietas experimentais, constituídas de banha de porco, um componente rico nesse tipo de nutriente. $\mathrm{O}$ aumento na ingestão de gorduras monoinsaturadas, juntamente com uma redução da oferta de carboidratos, induz aumento da fração HDL do colesterol, ainda que possa promover o aumento de peso ${ }^{23}$. Todavia, apesar do efeito positivo representado pelo aumento do HDL colesterol, a dieta HLP induz a mais alterações indesejáveis, tais como o aumento 
na glicemia e na trigliceridemia, do que efeitos positivos. De fato, Wolf ${ }^{24}$ denomina de "defensivo" o aumento do colesterol HDL induzido por dieta rica em gorduras e colesterol, de modo que esse tipo de dieta não deve ser encorajado.

Os dados do consumo de ração sugerem uma regulação da ingestão, pela quantidade de energias ingeridas, pois, embora as dietas estivessem "ad libitum", não houve um maior consumo semanal de energias por parte do grupo experimental por estar ingerindo uma dieta hiperenergética, confirmando a hipótese de que os animais controlam sua ingestão em função das necessidades energéticas ${ }^{25}$. No entanto, ao analisar o consumo total de energias ao longo das oito semanas, observou-se ingestão energética maior no grupo-experimental e suficiente para o acúmulo de tecido adiposo, de acordo com o trabalho de Pullar \& Webster ${ }^{26}$.

Klaus $^{18}$, comparando os efeitos de dietas isoenergéticas hiperlipídicas com duas diferentes relações proteína/carboidrato sobre a obesidade e o metabolismo energético em ratos, notou que houve uma hiperfagia ativa inicial seguida de um hiperconsumo passivo contínuo. Essa hiperfagia foi transitória e desapareceu quase completamente após três semanas. Estudos em humanos também sugerem que a densidade energética afeta a ingestão alimentar somente a curto prazo, enquanto a longo prazo esses efeitos são modulados e ocorre compensação 27 .

Segundo Dawson-Hughes ${ }^{28}$, o consumo diário de proteínas tem vários efeitos no cálcio do organismo, que resultam no aumento da excreção urinária de cálcio. Neste estudo foi realizada dosagem de cálcio sérico, mas não houve diferença entre os grupos.

Uma dieta rica em proteínas irá provocar um excesso de aminoácidos nos tecidos, utilizado como fonte de energia e neoglicogênese, liberando ureia contendo nitrogênio proveniente do metabolismo das proteínas formada no fígado a partir da amônia ${ }^{29}$. Considerando o alto teor de proteína das dietas experimentais, poderia ser esperado um aumento desse analito no soro dos animais experimentais. No entanto, isso não foi observado, provavelmente devido ao maior volume urinário dos animais experimentais (dado não mostrado).

A creatinina é um produto metabólico da degradação da creatina-fosfato no músculo. A sua produção é relativamente constante e depende da massa muscular. Valores aumentados de creatinina acontecem na insuficiência renal. Por outro lado, a ingestão de proteínas em quantidade suficientemente grande pode aumentar potencialmente o nível sérico de creatinina e diminuir sua depuração $0^{29,30}$. Esses dados explicam o resultado elevado da creatinina sérica dos animais experimentais que ingeriram a dieta hiperlipídico-proteica.

No presente estudo foi observada maior intensidade de esteatose hepática no grupo experimental. Já foi demonstrado que dietas alimentares produzem efeitos que atuam na bioquímica corporal e acúmulo de reservas, modificando morfologicamente vários órgãos. Esse efeito aparece não só em indivíduos adultos, mas também em recém-nascidos de mães cujas dietas foram modificadas ${ }^{17}$. Estudos indicam inclusive que a dieta materna pode causar um imprinting metabólico nos fetos, ou seja, modificam a expressão de genes, contribuindo para que o metabolismo desse indivíduo seja modificado ${ }^{31}$. Osei-Yiaman et al..$^{32}$ mostraram que dietas de alto teor de Lipídeos causam alterações metabólicas como hiperglicemia, resistência à insulina e esteatose hepática não alcoólica, o que corrobora os achados deste estudo.

\section{O N CLUS Ã O}

A dieta HLP com baixo teor de carboidratos, que em seres humanos é utilizada como emagrecedora, induziu a um significativo ganho de massa corporal, com aumento do tecido adiposo em ratos, quando comparada com consumo de dieta balanceada. A dieta HLP causou esteatose hepática e alterações em parâmetros bioquímicos, que representam uma piora da condição de saúde 
dos animais. Portanto, as dietas hiperlipídico-proteicas com objetivo de redução de peso corporal, embora eficazes segundo seus proponentes, podem levar a resultados contrários ao esperado.

\section{A GRADECIMENTOS}

A Fundação de Amparo à Pesquisa de Minas Gerais (Processo CDS 1282/05 e Processo APQ-25424.08/07) e da Universidade de Uberaba (Processos PROPEP 2004/069 e PAPE 2006/051).

\section{COLABORA D ORES}

A.J. BORBA realizou as dosagens bioquímicas e participou de todos os experimentos. M.G.M. ROCHA participou da elaboração das dietas e acompanhamento da ingestão alimentar e determinações de aspectos nutricionais das dietas ministradas. M.F. SILVA participou da análise estatística dos resultados e da elaboração e discussão de figuras e tabelas de resultados. D.T.S. TIBÚRCIO participou da definição da composição da dieta e elaboração do protocolo experimental, bem como orientou os estudos de ganho de peso e consumo de ração. S.A.L. PEREIRA orientou as análises histológicas dos fígados dos animais e discutiu os resultados desta parte. L.C. REIS foi o coorientador da pesquisa e participou da discussão dos resultados e redação do manuscrito. G. THEDEI JÚNIOR foi o delineador do projeto, orientador da execução da pesquisa e participou da discussão dos resultados e redação do manuscrito.

\section{REFERÊ N CIAS}

1. Dang MN, Hashem BE. The epidemiology of obesity. Gastroenterol Clin North Am. 2010; 39(1):1-7.

2. Oda E. The metabolic syndrome as a concept of adipose tissue disease. Hyperten Res. 2008; 7(31): 1283-91.

3. Flier JS. Obesity wars: molecular progress confronts an expanding epidemic. Cell. 2004; 116(2):337-50.

4. Boden G. Role of fatty acids in the pathogenesis of insulin resistance and NIDDM. Diabetes. 1997; 46(1):3-10.

5. Sumiyoshi M, Sakanaka M, Kimura Y. Chronic intake of high-fat and high-sucrose diets differentially affects glucose intolerance in mice. J Nutr. 2006; 136(3):582-87.

6. Deji N, Kume S, Araki S, Soumura M, Sugimoto T, Isshiki K. Structural and functional changes in the kidneys of high-fat diet-induced obese mice. Am J Physiol Renal Physiol. 2009; 296(1):118-26.

7. Charbonneau A, Unson CC, Lavoie JM. High-fat diet-induced steatosis reduces glucagon receptor content in rat hepatocytes: potential interaction with acute exercise. J Physiol. 2007; 579(1):255-67.

8. Blouet C, Mariotti F, Azzout-Marniche D, Bos C, Mathé $\mathrm{V}$, Tomé $\mathrm{D}$, et al. The reduced energ intake of rats fed a high-protein low carbohidrate diet explains the lower fat deposition, but macronutrient substitution accounts for the improved glycemic control. J Nutr. 2006; 136(7): 1849-54.

9. Weigle DS, Breen PA, MatthysCC, Callahan HS, Meeuws KE, Burden VR, et al. A high-protein diet induces sustained reductions in appetite, ad libitum caloric intake, and body weight despite compensatory changes in diurnal plasma leptin and ghrelin concentrations. Am J Clin Nutr. 2005; 82(1): 41-8.

10. Pichon L, Huneau JF, Fromentin G, Tomé D. A highprotein, high-fat, carbohidrate-free diet reduces energy intake, hepatic lipogenesis, and adiposity in rats. J Nutr. 2006; 136(5):1256-60.

11. Bahl M, Qayyum A, Westphalen AC, Noworolski SM, Chu PW, Ferrell L, et al. Liver steatosis: investigation of opposed-phase T1-weighted liver MR signal intensity loss and visceral fat measurement as biomarkers. Radiology. 2004; 249(1):160-6.

12. Akiyama T, Tachibana I, Shirohara H, Watanabe $N$, Otsuki M. High-fat hypercaloric diet induces obesity, glucose intolerance and hyperlipidaemia in normal adult male wistar rat. Diab Res Clin Pract. 1996; 31(1-3):27-35.

13. Duarte ACGO, Fonseca DF, Manzoni MSJ, Soave CF, Sene-Fiorese M, Dâmaso AR, et al. Dieta hiperlipídica e capacidade secretória de insulina em ratos. Rev Nutr. 2006; 19(3):341-8. doi: 10.1590/S1 415-52732006000300005.

14. Estadella D, Oyama LM, Dâmaso AR, Ribeiro EB, Nascimento CMO. Effect of palatable hyperlipidic diet on lipid metabolism of sedentary and exercised rats. Nutrition. 2004; 20(2):218-24.

15. Fam BC, Morris MJ, Hansen MJ, Kebede $M$, Andrikopoulos S, Proietto J, et al. Modulation of central leptin sensitivity and energy balance in a rat model of diet-induced obesity. Diabetes Obes Metab. 2007; 9(6):840-52. 
528 | A.J. BORBA et al.

16. Lehninger AL, David LN, Michael MC. Princípios de bioquímica. 6a ed. São Paulo: Sarvier; 2006. p.703-8.

17. Woods SC, Seeley RJ, Rushing PA, D'Alessio D, Tso P. A controlled high-fat diet induces an obese syndrome in rats. J Nutr. 2003; 133(4):1081-7.

18. Klaus S. Increasing the protein: carbohydrate ratio in a high-fat diet delays the development of adiposity an improves glucose homeostasis in mice. J Nutr. 2005; 135(8):1854-8.

19. Carvalheira JBC, Zecchin HG, Saad MJA. Bases moleculares e fisiológicas da resistência à insulina. Hipertensão. 2006; 5(1):33-8.

20. Nery M. Hipoglicemia como Fator Complicador no Tratamento do Diabetes Melito tipo 1. Arq Bras Endocrinol Metab. 2008; 52(2):288-98.

21. Fernandes $A A H$, Novelli ELB, Santana $Y$, Campos KE. Influência da dieta hipercalórica sobre parâmetros bioquímicos séricos, hepáticos e cardíacos em ratos. Nutr Pauta. 2004: 12(65):43-50.

22. Luengas-Escudero ME, Mejía-Aranguré JM, CruzRuíz M, Aguirre-Gas H, Carreño-Mejía E, Lerdo de Tejada-Hay A. Dyslipidemia associated with food. Gac Med Mex. 1997; 133(4):295-9.

23. Sociedade Brasileira de Hipertensão. I Diretriz brasileira de diagnóstico e tratamento da síndrome metabólica. Arq Bras Cardiol. 2005; 84(Suppl.1):3-28.

24. Wolf G. High-fat, high-cholesterol diet raises plasma HDL cholesterol: studies on the mechanism of this effect. Nutr Rev. 1996; 54(1 Pt 1):34-5.
25. Mahan LK, Escott-Stump S. Krause: alimentos, nutrição e dietoterapia. $10^{a}$ ed. São Paulo: Roca, 2002; p.13.

26. Pullar JD, Webster AJF. The energy cost of fat and protein deposition in the rat. Br J Nutr. 1977; 37(3): 355-63.

27. Westerpep-platenga MS. Effects of energy density of daily food intake on long term energy intake. Physiol Behav. 2004; 81(5):765-71.

28. Dawson-Huges B. Calcium and protein in bone health. Proc Nutr Soc. 2003; 62(2):505-9.

29. Lima RSN. Caminhando pela bioquímica. Fortaleza: Virtualbooks; 2003. p.138-43.

30. Ravel, R. Laboratório clínico. $6^{a}$ ed. Rio de Janeiro: Guanabara Koogan; 1997.

31. Edozien JC, Switzer BR. Influence of diet on growth in the rat. J Nutr. 1978; 108(2):282-90.

32. Osei-Hyiaman D, Liu J, Zhou L, Godlewski G, Harvey-White J, Jeong $W$, et al. Hepatic CB1 receptor is required for development of dietinduced steatosis, dyslipidemia, and insulin and leptin resistance in mice. J Clin Invest. 2008; 118(9):3160-9.

Recebido em: 11/6/2010

Versão final reapresentada em: 21/12/2010

Aprovado em: 22/2/2011 